\title{
A Quandary for Atypical Canal Pattern in Mandibular Second Premolar: A Case Report
}

\author{
${ }^{1}$ Dr. Isha Srivastava, ${ }^{2}$ Dr. Arun Verma, ${ }^{3}$ Dr. Divya Pandey \\ ${ }^{1,2,3}$ Conservative And Endodontics \\ Sardar Patel Post Graduate Institute Of Dental And Medical Sciences. Lucknow (Uttar Pradesh)
}

\begin{abstract}
Success of endodontic treatment requires the knowledge and morphology of root canal anatomy. Undetected additional canals in mandibular premolar is a common reason for endodontic failure. This presents with diagnostic difficulty and subsequent flare ups and poor prognosis. Location of additional canals is the key to successful endodontic management. This case report describes endodontic management with unusual morphological variations in canal anatomy of mandibular second premolar with two canals.
\end{abstract}

Keywords: Aberrant anatomy, mandibular second premolar, morphologic variations, two canals.

\section{Introduction}

The objective of endodontic treatment is to reduce or eliminate micro-organisms and their by-products from the root canal system which can be obtained by chemo-mechanical debridement, disinfection and three dimensional obturation of the root canal system with an inert filling material. Complex root canal anatomy, incorrect instrumentation of canal and incomplete obturation are the perpetrator for the endodontic failure and flare ups. ${ }^{12345}$ Detailed knowledge of root and root canal anatomy of various teeth and their numerous variations are obligatory to improve the inexorableness of endodontic therapy. ${ }^{6789}$ Mandibular premolars were considered as "Endodontist Enigma" because of the aberrations in their canal morphology when compared to any other tooth in oral cavity. ${ }^{10}$

Variations of root canal in premolar have been reported in the various literature. ${ }^{11}{ }^{12}$ The frequency of a second canal is $2.5 \%$ in mandibular second premolar has been reported by Vertucci who conducted a study on extracted teeth for anatomy of root canal. ${ }^{13}$ Tzanetakis et al. reported that the incidence of two or more canals in the mandibular second premolar can range from 1.2 to $34 \% .{ }^{14} 5.3 \%$ of mandibular second premolars had two canals with two foramen.$^{15}$ Ingle found, mandibular second premolars have only $12 \%$ chance of a second canal, $0.4 \%$ of a third canal. Harty, reported that there is $11 \%$ possibility of second canal. ${ }^{16-20}$ Thus, this case report attempts to alert the dental fraternity, that the presence of extra canal in mandibular second premolar, which if left untreated, will affect the prognosis of endodontic treatment.

\section{Case Report}

A 60 year old female patient was reported to Department of Conservative Dentistry and Endodontics in Sardar Patel Post Graduate Institute of Dental and Medical Sciences, Lucknow with the chief complaint of spontaneous pain in lower left back tooth region of jaw since 1 month. Pain was dull, intermittent, radiating in nature and aggrevates from hot beverages. Patient's medical history was non-contributory. Clinical examination revealed that in mandibular left first and second premolars, pulp were cariously exposed and were tender on percussion. There was no evidence of intraoral swelling and sinus present in relation to both the mandibular premolars. (Fig. 1).

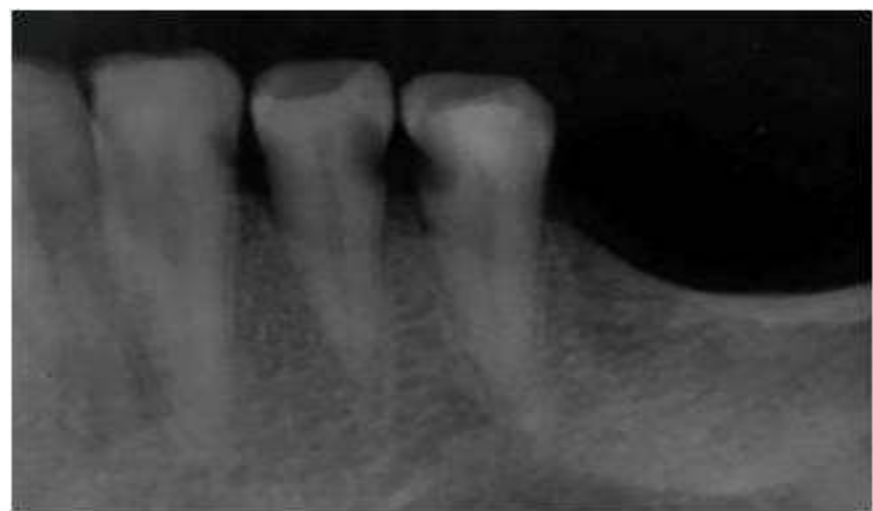

Fig. 1 : Pre operative radiograph of mandibular premolars 
Pulp vitality test using electric pulp tester yielded a response at a low current level than the adjacent and contralateral teeth that were normal. Radiographically, there was slight widening of lamina dura in both the mandibular premolars. Based on the clinical and radiographic findings, a diagnosis of chronic irreversible pulpitis with apical periodontitis was made and decided to perform root canal treatment of both the mandibular premolars of left side.

The treatment plan was explained to the patient and after obtaining her consent, the left lower mandibular premolars were anaesthetized with 2\% lidocaine (Lignox A, Warren Indoco) solution by way of inferior alveolar nerve block. The mandibular premolars can't be isolated with rubber dam as the adjacent tooth was not present in relation to mandibular second premolar. After excavation of dental caries, the carious part were restored with composite resin of both the mandibular premolars.(Fig.2) Access cavity were prepared with Endo access and Endo Z bur (Dentsply Maillefer, Ballaigues, Switzerland) in mandibular $1^{\text {st }}$ and $2^{\text {nd }}$ premolar under dental operating microscope .

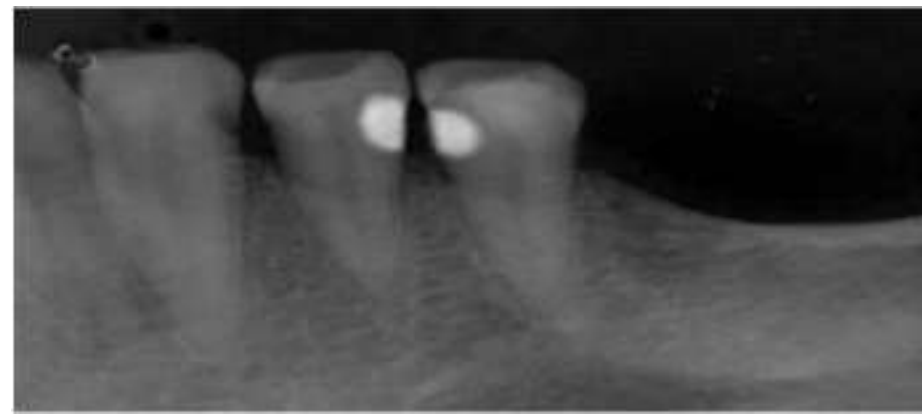

Fig2: Caries were restored with composite resin

One canal was located in the center of mandibular $1^{\text {st }}$ premolar and one canal in mandibular second premolar which is located buccally. therefore, to gain sufficient access to an additional canals in mandibular second premolar, the conventional access opening were modified into one that was wider and buccolingually oriented. On careful exploration of the pulp chamber floor with an endodontic explorer DG- 16 (Dentsply, Maillefer, Ballaigues [VD], Switzerland), one more canal orifice was located i.e. lingually in mandibular $2^{\text {nd }}$ premolar. (Fig.3) The canal patency was obtained using size 10 no. K file and intra oral periapical radiograph were taken at different angulations i.e., mesial and distal to confirm an additional canal in mandibular $2^{\text {nd }}$ premolar.

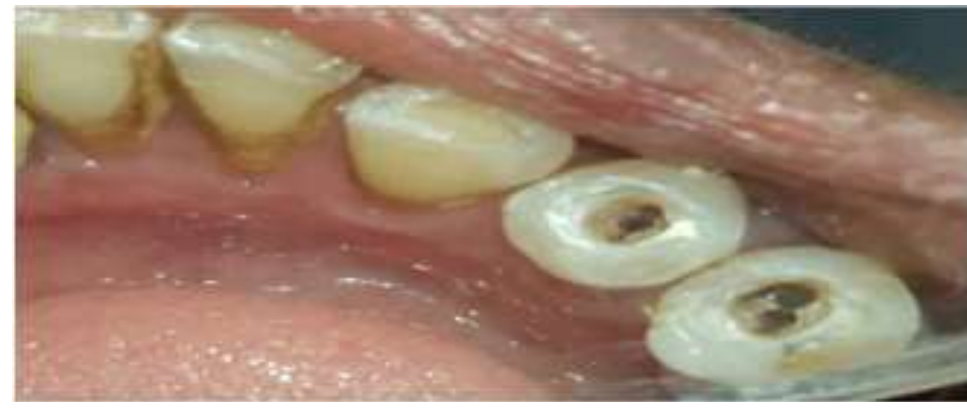

Fig 3: Canal orifices were located in mandibular premolars

After locating the canals, working length of both the mandibular premolars were established using 15 no. K File and were confirmed with electronic apex locator (Root ZX, J. Morita, Tokyo, Japan) (Fig. 4).

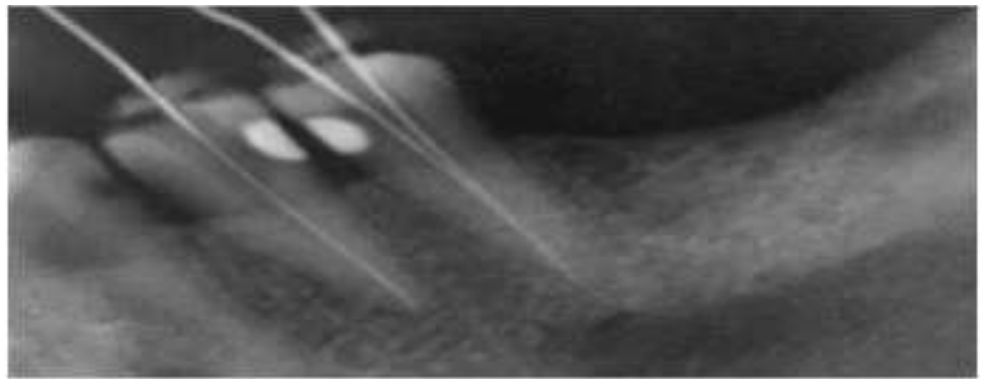

Fig. 4 : Working length were determined of mandibular premolars 
The canals orifices were enlarged with size 2 and 3 Gates Glidden drills (Dentsply Maillefer, Ballaigues, Switzerland) using a brushing motion, and mechanical instrumentation of root canals were done with Protaper next files rotary system (Dentsply Maillefer, Ballaigues, Switzerland) using crown down technique to size X3 in mandibular first premolar and till X2 in mandibular second premolar. 2.5\% sodium hypochlorite $(\mathrm{NaOCl})$ solution were used as an irrigant for copious irrigation of canals and were activated with EndoActivator system (Dentsply Tulsa Dental Specialties, Tulsa, OK, USA) to maximize its effect. After completion of cleaning and shaping, the root canals were dried with sterile paper points. Calcium hydroxide as an intracanal medicament was placed inside the canals of both the mandibular premolars for disinfection of the canals. Access cavities were sealed with temporary restorative material i.e., Cavit (ESPE, Seefeld, Germany). Patient was recalled after 3 days and was found asymptomatic in clinical examination. Calcium hydroxide was removed from the canals with ultrasonic activation of 17\% EDTA and 2.5\% sodium hypochlorite solution. After removal of intracanal medicament, the master cone radiograph was taken of both the mandibular premolars(Fig. 5). The canals were dried with sterile paper points and were obturated with gutta percha points and a resin based sealer- AH Plus sealer (De Trey Dentsply, Konstanz, Germany). A post-obturation radiograph was obtained to assess the quality of obturation (Fig. 6).

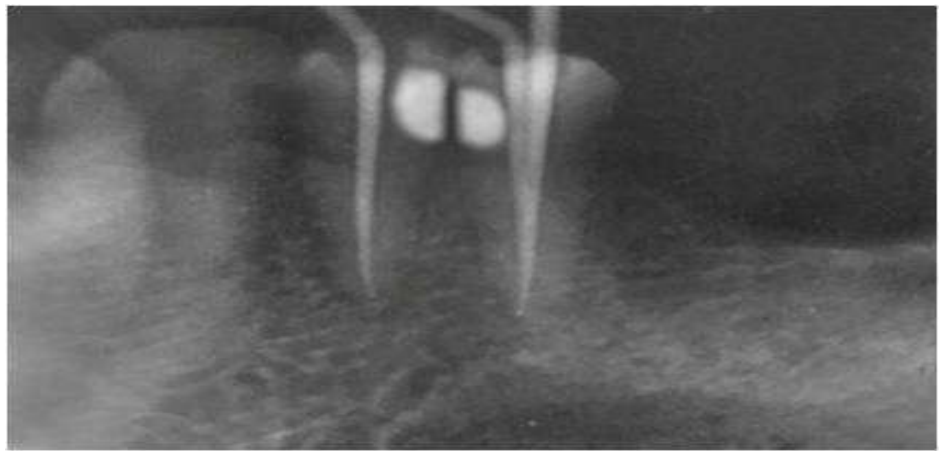

Fig. 5: Master cone radiograph of mandibular premolars

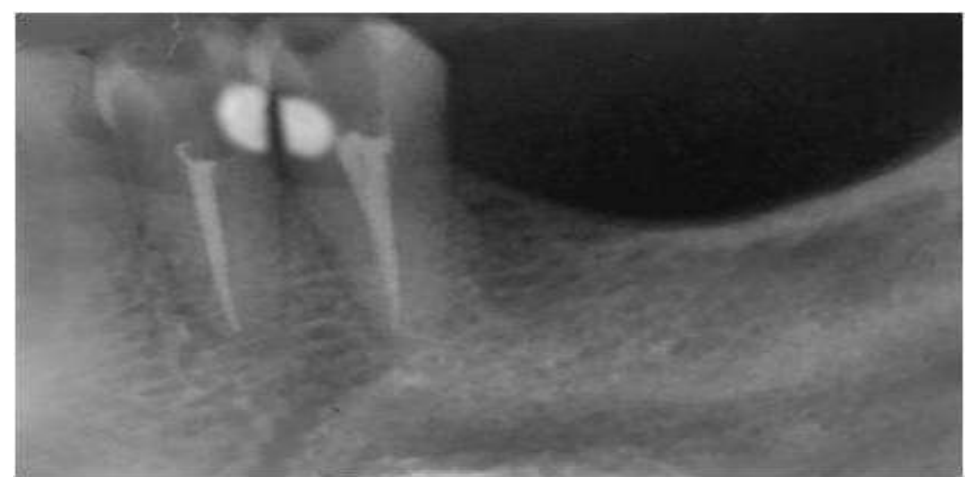

Fig. 6: Obturation of mandibular premolars

The access cavities were sealed with temporary restorative material i.e., Cavit. Patient was recalled after 7 days and post endodontic restorations were done with composite resin restorative material (Herculite XRV Ultra, Kerr, Bioggio, Switzerland) (Fig. 7).

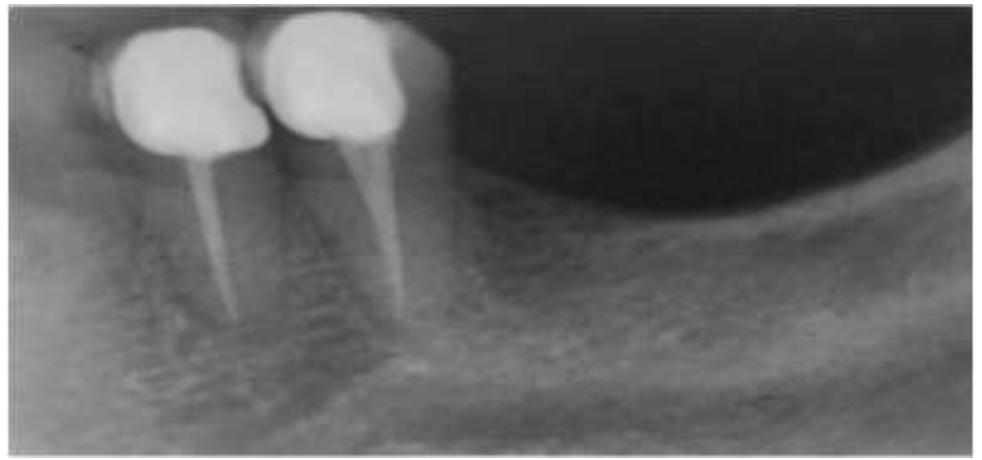

Fig. 7: Post endodontic restoration done with composite resin 
Patient was on follow up for 6 months. Clinical examination showed that the patient was symptom-free with no tenderness on percussion; the follow-up radiographs showed a continuous lamina dura with no periapical changes i.e., normal periodontium in both the mandibular premolars.

\section{Discussion}

Mandibular premolars have the highest failure rate at $11.45 \%$ amongst all teeth. ${ }^{21}$ Scott and Turner named the accessory root of mandibular premolar as Tomes root. ${ }^{22}$ Sert and Bayrili reported that prevalance of extra roots and accessory canals is more common in females(44\%) as compared to males(34\%).Pineda and Kuttler ${ }^{24}$ and Vertucci ${ }^{25}$ developed a classification for canal anatomy and classified them as Type I to Type VIII. Sert and Bayirli ${ }^{26}$ reported additional 14 new canal types (Type IX-Type XXIII). A clinician should be aware about the anatomical variations, internal and external morphology of teeth especially extra canals and roots $^{2728}$ and also assess every tooth requiring a root canal treatment carefully to avoid missing any additional canal. A high quality pre-operative radiographs taken at different horizontal angulations and carefully evaluated to detect the presence of extra root canal or internal morphology of root canal system. ${ }^{29}{ }^{30}$ Martinez-Lozano et al. have suggested a 40-degree mesial angulation of the $\mathrm{x}$-ray beam to identify additional canals for success of endodontic treatment. ${ }^{31}$ Various diagnostic aids are available such as Sodium hypochlorite 'champagne bubble' test, examining the floor of the pulp chamber with a sharp explorer, ultrasonic tips and staining with $1 \%$ methylene blue dye were also used in detecting the extra canal. ${ }^{32}$.

The dental operating microscope is another important tool in the contemporary endodontic practice and is gaining popularity among endodontists now a days. It improves visualization, quality of treatment, enhances ergonomics, allows for digital documentation and communication ability through integrated videos. ${ }^{33}$ Successful and predictable endodontic treatment requires knowledge of biology, physiology and root canal anatomy. The root canal morphology of mandibular premolars can be highly variable and complex and it is often a challenging task to carry out successful endodontic therapy with such teeth. Therefore, the primary step in root canal treatment is the identification of the internal morphology of root canal system as precisely as possible, for the success of endodontic treatment and to prevent endodontic failure and flare ups. ${ }^{29}{ }^{30}$

\section{Conclusion}

The purpose of endodontic treatment is complete debridement of the root canals followed by its obturation to create a hermetic seal. A thorough and methodical approach is needed for treating the complex root canal morphology. Complex canal anatomies and its diagnosis can be best diagnosed by multi-angled diagnostic radiographs, dental operating microscope, endodontic explorer DG- 16 and various dyes. The clinician must carefully interpret the pre-operative radiographs and must be vigilant on clinical inspection of the floor of the pulp chamber to avoid missing any extra canal for a successful endodontic treatment outcome.

\section{References}

[1]. Rodig T, Hulsmann M. Diagnosis and root canal treatment of a mandibular second premolar with three root canals. IntEndod J 2003;36:912-919.

[2]. Gandhi B, Patil AC. Root canal treatment of a mandibular second premolar with three roots and canals-an anatomic variation. J Dent 2013;10(6):569-574.

[3]. Cleghorn BM, Christie WH, Dong CCS. The root and root canal morphology of the human mandibular second premolar: a literature review. J Endod 2007;33:1031-1037

[4]. Kottoor J, Albuquerque D, Velmurugan N, Kuruvilla J. Root anatomy and root canal configuration of human permanent mandibular premolars: a systematic review. Anat Res Int 2013;1-14.

[5]. Mokhtari H, Niknami M,Zand V. Managing a mandibular second premolar with three-canal and taurodontism: a case report. Iranian Endod J 2013;8(1):25-28.

[6]. Singh S, Pawar M. Root canal morphology of South Asian Indian mandibular premolar teeth. J Endod 2014;40(9):1338-1341.

[7]. Hariharavel VP, Kumar AA, Ganesh C, Annamalai S, Ramar K, Aravindhan R. Root canal treatment of mandibular second premolar with three separate roots and canals using spiral computed tomographic. Case Reports Dent 2014; 1-4.

[8]. Lotfi M, Vosoughhosseini S, Zand V, Fatemi A, Shyezadeh V, Ranjkesh B.A mandibular second premolar with three canals and atypical orifices. J Oral Sci 2008;50(3):363-6.

[9]. Cleghorn BM, Christie WH, Dong CCS. Anomalous mandibular premolars: a mandibular first premolar with three roots and a mandibular second premolar with a C-shaped canal system. IntEndod J 2008;41:1005-1014

[10]. Slowey RR. Root canal anatomy. Road map to successful endodontics. Dent Clin north Am 1979;23:555-73

[11]. Kerekes K, Tronstad L. Morphometric observations on root canals of human

[12]. premolars. J Endod 1977;3:74-9.

[13]. 12.Vertucci FJ. Root canal anatomy of the human permanent teeth. Oral Surg Oral Med Oral Pathol 1984;58:589-99.

[14]. 13. Vertucci FJ. Root morphology of mandibular premolars. J Am Dent Assoc 1978;97:47-50

[15]. 14.Tzanetakis GN, Lagoudakos TA, Kontakiotis EG. Endodontic treatment of a mandibular second premolar with four canals using operating microscope. J Endod. 2007;33:318-321.

[16]. Lin Z, Ling J, Jhugroo A. Mandibular first and second premolars with three canals. Internet J Dent Sci 2006;4:

[17]. ElDeeb ME. Three root canals in mandibular second premolars - literature review and case report. J Endod 1982;8:376-7.

[19]. Trope M, Elfenbein L, Tronstad L. Mandibular premolars with more than one root canal in different race groups. J Endod 1986;12:343-5.

[21]. Wong M. Four root canals in a mandibular second premolar. J Endod 1991;17:125-6. 
[23]. Holtzman L. Root canal treatment of mandibular second premolar with four root canals: A case report. Int Endod J 1998;31:364-6.

[25]. Macri E, Zmener O. Five canals in a mandibular second premolar. J Endod 2000;26:304-5

[27]. Ingle J, bakland L. Endodontics 5th ed. Hamilton:B C Deckor;20002

[28]. Scott, Turner C 2nd. The anthropology of modern human teeth. Cambridge: Cambridge university press;2000

[29]. Sert S, bayirili GS. Evalaution of root canal configuration of maxillary and mandibular permanent teeth by gender in Turkish population. J Endod

[30]. Pineda F, Kuttler Y. Mesiodistal and buccolingual roentgenographic investigation of 7,275 root canals. Oral Surg Oral Med Oral Pathol 1972;33:101-10.

[31]. Vertucci FJ. Root canal anatomy of the human permanent teeth. Oral Surg Oral Med Oral Pathol 1984;58:589-99

[32]. Sert S, Bayirli GS. Evaluation of the root canal configurations of the mandibular and maxillary permanent teeth by gender in the Turkish population. J Endod 2004;30:391-8

[33]. Molander A, Reit c, dahlen g, Kvist T. Microbiological status of root filled teeth with apical periodontitis. Int Endod j 1998;31:1-7

[34]. Sundqvist G, Fidgor D, Persson S, Sjogren U. Microbiologic analysis of teeth with failed endodontic treatment and outcomeofconservative treatment. Oral surg oral med oral path oral radiol Endod 1998;85:86-93

[35]. England MC Jr, Hartwell GR, Lance JR. Detection and treatment of multiple canals in mandibular premolars. J Endod 1991;17:1748.

[36]. Hulsmann M. Mandibular first premolar with three root canals. Endod Dent Traumatol 1990;6:189-91

[37]. Martinez-lozano MA, Forner-Navarro L, Sanchez-Cortes JL. Analysis of radiologic factors in determining premolar root canal systems. Oral Surg Oral Med Oral Pathol Oral Radiol Endod 1999;88:719-22.

[38]. Friedman S, Moshonov J, Stabholz A. Five root canals in a mandibular first molar. Endod Dent Traumatol. 1986 Oct;2(5):226-8

[39]. Kersten DD, Mines P, Sweet M. Use of the microscope in Endodontics: Results of a questionnaire. J Endod 2008;34:804-

[40]. Glenn A, Van AS. Use of the dental operating microscope in laser dentistry: Seeing the light. J Laser Dent 2007;15:122-9. 